BRAD HANSON, UC Cooperative Extension Weed Specialist, Department of Plant Sciences, University of California, Davis; ALBERT FISCHER, Professor, Department of Plant Sciences, University of California, Davis; ANIL SHRESTHA, Associate Professor, Department of Plant Sciences,

California State University, Fresno; MARIE JASIENIUK, Associate Professor, Department of Plant Sciences, University of California, Davis; ED PEACHEY, Department of Horticulture, Oregon State University, Corvallis; RICK BOYDSTON, USDA Agricultural Research Service, Prosser, Washington; TIM MILLER, Mount Vernon Research and Extension Center, Mount Vernon, Washington; and KASSIM AL-KHATIB, UC Cooperative Extension Weed Specialist and Director of Statewide IPM Program, Department of Plant Sciences, University of California, Davis

\section{Selection Pressure, Shifting Populations, and Herbicide}

\section{Resistance and Tolerance}

eror

erbicides can provide impressive levels of weed

control in many crop and noncrop situations; however, not all weedy species are equally controlled, due to varying levels of natural tolerance or evolution of herbicide-resistant weed biotypes. Herbicides impose a great degree of selection pressure on weed populationsand if the same herbicide or herbicides with the same mode of action are used repeatedly, herbicide-resistant or herbicide-tolerant species can build up in the population after several generations (fig. 1).

\section{HeRBicide tOlerAnCE AND WEEd SHIFTS}

Weedy plants can be tolerant of herbicides due to a variety of temporal, spatial, or physiological mechanisms. For instance, a weed may avoid control efforts if it emerges after a burndown herbicide is applied or completes its lifecycle before a postemergence herbicide is applied. Similarly, large-seeded or perennial weeds can emerge from deeper in the soil and may avoid germinating in soil treated with a preemergence

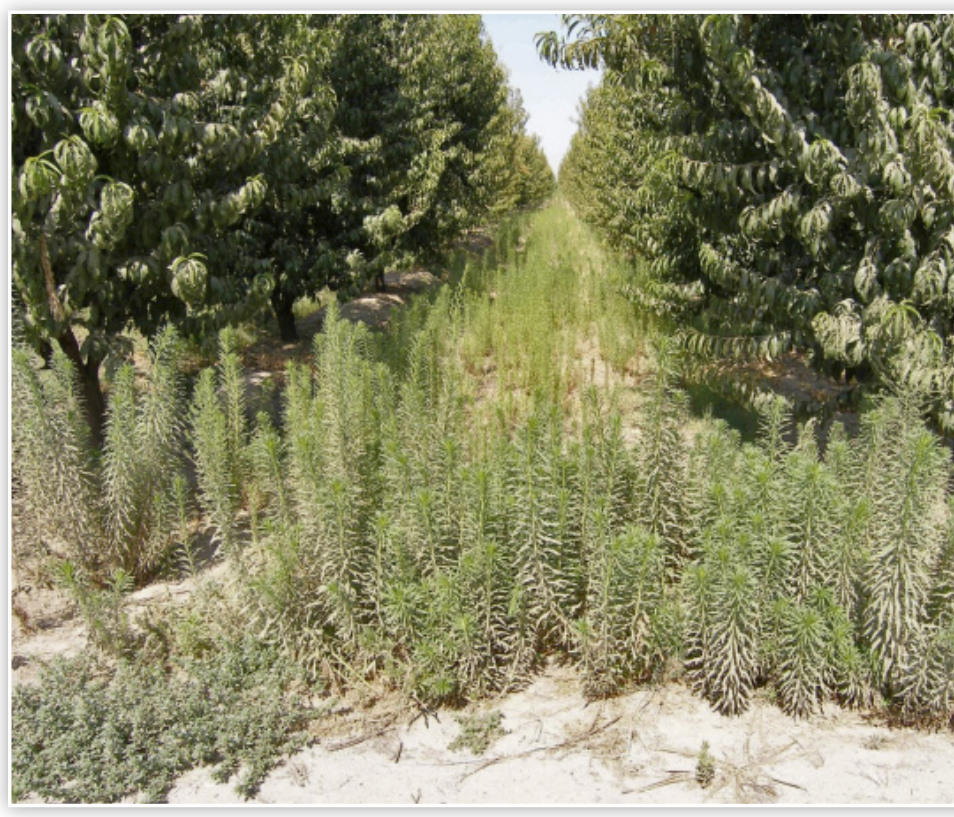

Figure 1. Stone fruit orchard in Fresno County, California, dominated by glyphosate-resistant horseweed. Reliance on one method of weed control imposes selection pressure on tolerant species or resistant biotypes. Photo: Anil Shrestha. 
herbicide. Other weedy species have physiological mechanisms of tolerance and avoid control through reduced herbicide uptake or translocation, rapid detoxification, or insensitive target sites.

Regardless of the mechanism of tolerance, repeated use of an herbicide can lead to weed shifts in which weed populations become dominated by species that are not affected by the weed control measures used. A classic example of a weed shift in response to herbicides is the change from primarily broadleaf weeds to grass weeds in cereal production after the introduction of the broadleaf herbicide 2,4-D. Weed shifts can also occur following overuse of nonchemical weed control techniques, such as flame weeding or mowing, that tend to favor populations of grass weeds.

\section{HeRBicide RESISTANCE}

Herbicide resistance in weeds is an evolutionary process and is due in large part to selection with repeated use of the same herbicide or products with the same mode of action. Herbicides do not cause resistance; instead, they select for naturally occurring resistance traits. On a population level, organisms occasionally have slight natural mutations in their genetics; some of these are lethal to the individual, some are beneficial, and some are neutral. Occasionally, one of these chance mutations affects the target site of an herbicide such that the herbicide does not affect the new biotype. Similarly, mutations can affect other plant processes in a way that reduces the plant's exposure to the herbicide due to reduced uptake or translocation or through more rapid detoxification. Whatever the cause, under continued selection pressure with the herbicide, resistant plants are not controlled and their progeny can build up in the population (fig. 2). Depending on the initial frequency of the resistance gene in the population, the reproductive ability of the weed, and the competition, it may take several (or many) generations until the resistance problem becomes apparent.

\section{Mechanisms of Herbicide Resistance}

Two general types of mechanisms confer resistance to herbicides in weeds. Some mechanisms are related to the specific site of action of the herbicide in the plant, and others involve processes not related to the mechanism by which herbicides kill plants; these two types are known as target-site and non-target-site mechanisms, respectively. A certain weed biotype may be resistant to more than one herbicide. Herbicide cross-resistance occurs when an individual plant is resistant to two different herbicides via the

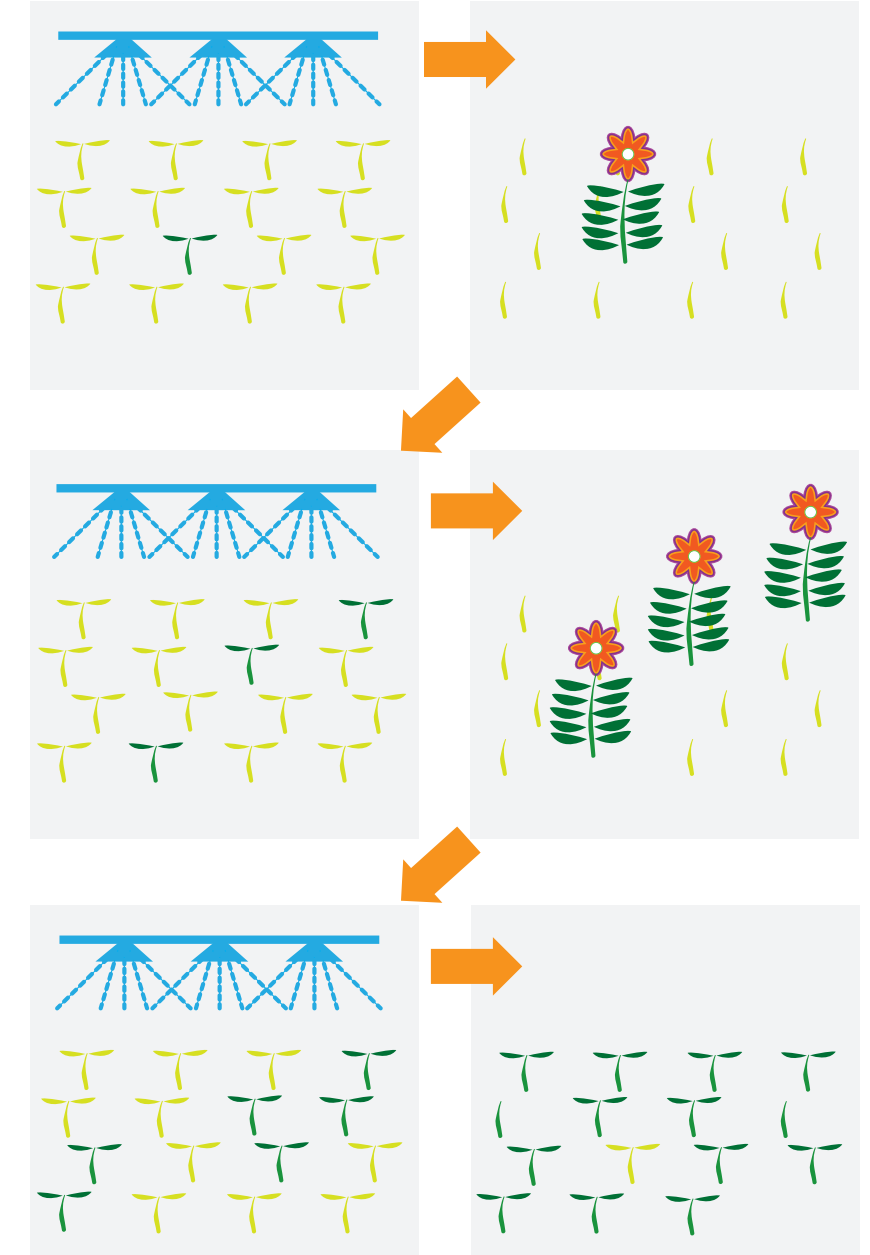

Figure 2. Infrequently, an individual weed develops a mutation that confers resistance to an herbicide or group of herbicides, and it survives and reproduces. After several generations and repeated selection with the same or similar herbicides, the resistant biotype can become dominant in the population. 
same mechanism of resistance. In this case, resistance is endowed by a single physiological process operating in common for all the herbicides involved. Multiple resistance results from selection by the simultaneous or sequential use of different herbicides, such that resistance to each herbicide is endowed by a different mechanism.

\section{Target-Site Resistance}

Herbicides usually affect plants by disrupting the activity of a specific protein (enzyme) that plays a key role in plant biochemical process. Target-site resistance occurs when the target enzyme becomes less sensitive or insensitive to the herbicide. The loss of sensitivity is usually associated with a mutation in the gene coding for the protein and can lead to conformational changes in the protein's structure. These physical changes can impair the ability of one or more herbicides to attach to the specific binding site on the enzyme, thus reducing or eliminating herbicidal activity. Although changes in protein structure occasionally result in reduced biological functionality of the enzyme and a related "fitness cost" (such as decreased photosynthetic efficiency), many target-site mutations do not have an observable fitness cost. Certain herbicide groups are particularly vulnerable to developing target-site resistance, because resistance can be endowed by several mutations, thus increasing the probability of finding resistant mutants in weed populationseven in those not previously exposed to that herbicide group. For example, specific mutations resulting in seven different amino acid substitutions in the acetolactate synthase (ALS) gene are known to confer resistance to ALS-inhibiting herbicides in weed biotypes selected under field conditions. Something similar occurs with the grass herbicides that inhibit the enzyme acetyl coenzyme A carboxylase (ACCase). In these cases, at least five point mutations (causing amino acid substitutions within the gene) are associated with cross-resistance patterns. These can be observed at the whole plant level and involve four classes of ACCase-inhibiting herbicides. The existence of so many mutations conferring resistance is the reason that resistance to these herbicides is frequently found and can evolve rapidly. Resistance to glyphosate can also be target-site mediated in some cases.

\section{Non-Target-Site Resistance}

Several mechanisms confer resistance to herbicides without involving the active site of the herbicide in the plant. Of these, the best known is the case of metabolic resistance due to an enhanced ability to metabolically degrade the herbicide. Non-target-site herbicide resistance has been well demonstrated for several gene families associated with cytochrome P450 monoxidases, glutathione transferases, and glycosyltransferases. Most of these non-targetsite resistance mechanisms are also present in cultivated plants and are the reason that many herbicides can be used selectively without injuring crops. Non-target-site resistance can evolve from the intensive use of diverse and unrelated selective herbicides that are similarly effective on a certain weed species and share a detoxification pathway or a mechanism precluding their accumulation at the target site (exclusion or sequestration) that is relatively common in plants. The management of non-targetsite herbicide resistance often represents a greater challenge than management of target-site resistance, because a simple change in herbicide mode of action may not alleviate the problem.

Reduced herbicide absorption or translocation (or both) can contribute to resistance in certain biotypes. These have generally been accessory mechanisms that contribute toward resistance in addition to major resistance mechanisms. However, recent evidence suggests that changes in absorption or translocation contribute importantly to glyphosate resistance in several weed biotypes.

\section{Glyphosate Resistance}

Glyphosate was used as a broad-spectrum, nonselective herbicide for nearly 40 years, with few concerns about resistance until the mid1990s. A number of factors have combined to increase the selection pressure for glyphosate-resistant weeds in several cropping systems. These include an increase in reduced- or no-tillage systems that depend on preplant weed control with glyphosate; the development of glyphosate-tolerant (Roundup Ready) crops in which glyphosate can be used during the growing season; environmental quality concerns (about groundwater) that have reduced the use of some preemergence herbicides; and a significant decrease in glyphosate 
prices. Since the initial report of a glyphosate-resistant weed (rigid ryegrass in Australia) in 1996, a total of 24 glyphosateresistant species have been reported around the world, and 14 of these are present in the United States. There appear to be several target-site and non-target-site mechanisms of resistance to glyphosate.

Target site. Glyphosate inhibits the enzyme 5-enolpyruvylshikimate-3-phosphate synthase (EPSPS) in the shikimate pathway. Inhibition of EPSPS by glyphosate causes an increase in shikimate and leads to plant death by disrupting several key metabolic processes. Resistance to glyphosate results from point mutations in the EPSPS gene, causing amino acid substitutions in the protein that affect the ability of the glyphosate molecule to bind to the enzyme; the enzyme is thus less sensitive to inhibition by glyphosate. These mutations confer moderate levels of resistance, which are nevertheless enough to enable plants to survive and selection for resistance to occur when glyphosate is applied repeatedly.

Non-target site. The ambimobile nature of glyphosate transport within plants (moving with both water and photosynthates) is a major reason for its effectiveness, and alterations in glyphosate translocation within the plant can confer relatively high levels of resistance in certain weeds. In certain glyphosate-resistant biotypes of Lolium spp. (Australia) and horseweed (United States), glyphosate failed to accumulate in growing points and roots and tended to remain concentrated in the leaves rather than translocating throughout the plant. For the most part, the precise mechanisms contributing to reduced translocation are not yet well understood, and details are still being elucidated.

\section{Current Status of Herbicide Resistance in Weeds}

Herbicide-resistant weeds are an issue around the world; but the greatest problems with resistance tend to be found in countries with highly industrialized agricultural cropping systems, due to their greater reliance on herbicides. Herbicide-resistant weed biotypes have been reported in at least 60 countries and include

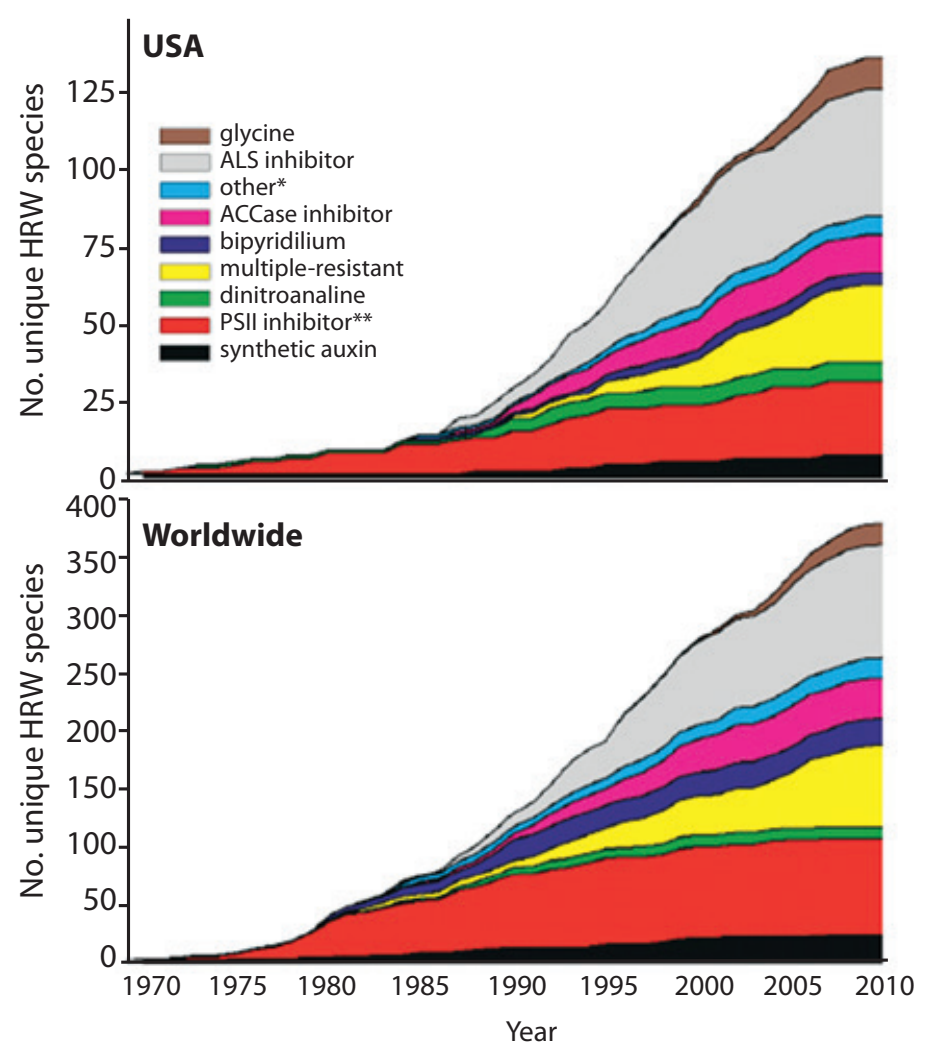

Figure 3. Chronological increase in reports of herbicide-resistant weeds (HRW) in the United States and worldwide. Source: Data compiled from the International Survey of Resistant Weeds (www.weedscience.org).

about 350 unique species-herbicide group combinations worldwide (fig. 3). Due to intensive, high-input cropping systems, the United States has a greater number of resistant biotypes (129) than any other country, followed by Australia (54), Canada (51), Spain and France (32 each), and Israel, United Kingdom, Germany, and Brazil (22-25 each).

Herbicide-resistant weeds around the world and throughout the United States are dominated by the photosystem II inhibitors and by ALS inhibitors as a result of the widespread use of these diverse herbicide classes in broad-acreage cereal and grain crops. Some of the most troubling herbicide-resistant biotypes are multiple-resistant 
Table 1. Factors contributing to increased selection pressure for herbicide-resistant weeds

\section{Cropping system \\ characteristics}

little or no crop rotation

little or no preplant or in-season tillage

low crop competition

little or no herbicide $(\mathrm{MOA})$ rotation

\section{Weed characteristics}

annual growth habit

high seed production

little seed dormancy

some seed longevity in seed bank

high frequency of resistance traits

multiple generations per year

mechanisms for gene flow

(pollen or seed)

little or no fitness penalty

for resistance trait

highly susceptible to the herbicide

\section{Herbicide characteristics}

single site of action

high efficacy

high use rate (relative to amount needed)

long soil residual activity

high frequency of use biotypes. (One population of rigid ryegrass in Australia is reported to be resistant to nine different modes of action.) In vineyard and orchard systems, several regions have reported substantial problems with resistance to glycines (glyphosate) and paraquat, as well as problems with multiple-resistant biotypes due to repeated use of postemergence materials.

\section{Management of Herbicide-Resistant Weeds}

A number of factors affect the degree of selection pressure for herbicide-resistant weeds (table 1). However, if preventive measures are taken to reduce selection pressure, herbicide resistance can be avoided or delayed. As outlined previously, repeated use of the same herbicide or herbicides with the same mode of action can select for weeds that are resistant to or tolerant of that mode of action. As an herbicide controls the susceptible biotypes, its repeated use causes the resistant biotypes to gradually build up in the population (see fig. 2). The adage "why fix something that is not broken" may not be applicable to herbicide-resistance management. For example, it is tempting to repeatedly use a certain herbicide that is very effective against a certain weed species or a community of weeds. However, such a process imposes a higher selection pressure on the target weed and ultimately leads to the buildup of a resistant population. Therefore, a major goal of herbicideresistance management is to reduce selection pressure. In this context, rotation (of crops and herbicides) and tank mixes become important resistance-management tools and often are used as the first line of defense against the selection of herbicide-resistant weeds.

Rotation can mean the use of different crops in a sequence, as in the case of annual cropping systems. In this type of cropping system, herbicides with different modes of action can be used in different phases of the rotation. Resistance to one weed control tactic does not easily evolve for several reasons. The weed populations are disrupted by the use of herbicides with different modes of action and also by the cultural operations that differ for each particular crop. For example, time of planting, type of tillage, and use of interrow operations may vary for these different crops, thus creating an unfriendly environment for weeds in which to adapt because of these continuous changes in selection pressure.

However, in perennial cropping systems, like orchards and vineyards, it is impractical to frequently rotate crops. Similarly, crop rotation opportunities can be limited by economic or environmental constraints. Noncrop areas such as roadsides, canal banks, and industrial sites also have few rotational alternatives. Therefore, in these systems, rotation or tank mixes of herbicides with different modes of action should be a part of the management plan to prevent the buildup of weeds resistant to those particular modes of action. When herbicides with different modes of action are used in rotation or mixtures, the selection pressure for any one herbicide is reduced. Thus, the weeds will have difficulty adapting to this continuous alteration in selection pressure.

Selection pressure on susceptible weeds from herbicides with longer residual activities is higher than that from herbicides with shorter or no residual activities, because one treatment can result in the exposure of multiple weed cohorts (i.e., flushes) to the herbicide. However, when herbicides with no residual activity are used multiple times in a season, selection pressure is equally high and can lead to selection for herbicide-resistant weeds, as has been observed with glyphosate-only weed control programs. In fact, short-term residual herbicides in combination with postemergence herbicides are being recommended for management of glyphosate-resistant weeds in many cropping systems.

\section{Conclusions Regarding Herbicide-Resistant Weeds}

Resistance mitigation seeks to diversify weed control methods in order to delay the evolution process; it does this by reducing the selection pressure exerted through the use of herbicides. Targetsite resistance is conferred by an alteration that causes loss of plant sensitivity to herbicides with specific mechanisms of action. It is 
clear, therefore, that one way of dealing with the problem is by switching to another herbicide that is effective on the same weed species but that has a different mechanism of action (MOA). The use of herbicide mixtures or sequences involving herbicides with different mechanisms of action can protect the herbicides and delay the evolution of resistance to both, since mutants with resistance to one herbicide would be controlled by the other herbicide and vice versa. However, the recurrent use of the same herbicide mixture could theoretically select for biotypes with resistance to both herbicides (multiple resistance).

Non-target-site resistance may involve different herbicides and the enhanced expression of mechanisms that are common in plants and thus easily selected for. If several herbicides share a common degradation route, such as the ubiquitous $\mathrm{P} 450$ monoxidation, their use will select for the same mechanism of resistance in biotypes that will be resistant to all the herbicides, even if these herbicides are used in mixtures or sequences with each other. Thus, combining or changing herbicides to control non-target-site-resistant biotypes becomes very difficult. Nontarget-site resistance may involve the accumulation of genes contributing partial resistance levels.

From this discussion of resistance mechanisms in herbicide-resistant weeds, it should be clear that resistance cannot be mitigated only by switching or combining herbicides in production systems that rely solely on the intensive use of selective herbicides for weed control. Instead, herbicide-resistance management requires the integrated diversification of chemical and nonchemical weed control methods to reduce selection pressure for resistant weed biotypes. Herbicides are one of the most effective tools for weed management; however, they must be used judiciously. They should be one of the many tools in a weed-management toolbox rather than the only tool, or else we are at risk of losing effective herbicides due to the evolution of herbicide-resistant weeds.

\section{FOR MORE INFORMATION}

To order or obtain ANR publications and other products, visit the ANR Communication Services online catalog at http://anrcatalog.ucanr.edu or phone 1-800-994-8849. You can also place orders by mail or FAX, or request a printed catalog of our products from

University of California

Agriculture and Natural Resources

Communication Services

1301 S. 46th Street

Building 478 - MC 3580

Richmond, CA 94804-4600

Telephone 1-800-994-8849; 510-665-2195

FAX 510-665-3427

E-mail: anrcatalog@ucanr.edu

(92013 The Regents of the University of California

Agriculture and Natural Resources

All rights reserved.

\section{Publication 8493}

ISBN-13: 978-1-60107-844-5

The University of California Division of Agriculture \& Natural Resources (ANR) prohibits discrimination against or harassment of any person participating in any of ANR's programs or activities on the basis of race, color, national origin, religion, sex, gender identity, pregnancy (which includes pregnancy, childbirth, and medical conditions related to pregnancy or childbirth), physical or mental disability, medical condition (cancer-related or genetic characteristics), genetic information (including family medical history), ancestry, marital status, age, sexual orientation, citizenship, or service in the uniformed services (as defined by the Uniformed Services Employment and Reemployment Rights Act of 1994: service in the uniformed services includes membership, application for membership, performance of service, application for service, or obligation for service in the uniformed services) or any person in any of its programs or activities.

University policy also prohibits retaliation against any employee or person participating in any of ANR's programs or activities for bringing a complaint of discrimination or harassment pursuant to this policy. This policy is intended to be consistent with the provisions of applicable State and Federal laws.

Inquiries regarding the University's equal employment opportunity policies may be directed to Linda Marie Manton, Affirmative Action Contact, University of California, Davis, Agriculture and Natural Resources, One Shields Avenue, Davis, CA 95616, 530-752-0495. For assistance in downloading this publication, telephone 530-754-3927.

An electronic copy of this publication can be found at the ANR Communication Services catalog website, http://anrcatalog.ucanr.edu/.

UC This publication has been anonymously peer reviewed for technical accuracy by University of California scientists and other qualified professionals. This review REVIEWED process was managed by ANR Associate Editor for Agricultural Pest Management Joe Nunez. 